\title{
De Cádiz a México. La cuestión de los institutos literarios (1823-1833)
}

Rosalina Ríos Zúñiga*

$\mathrm{E}$

n 1826, una noticia en Águila Mexicana refirió la inauguración solemne de un Instituto $\mathrm{Na}$ cional de Ciencias, Literatura y Artes en el Aula Mayor de la Universidad de México. Los objetivos de tal institución, como lo señaló en el discurso inaugural Andrés Quintana Roo, estarían "no en enseñar o profesar una ciencia $o$ arte particular, sino a cuidar del adelantamiento y perfección de todas". El carácter de nacional que le fue conferido demuestra sin duda, el interés del gobierno en el desarrollo de

- Mi reconocimiento a Enrique González, quien hizo críticas e importantes sugerencias a las distintas versiones del presente trabajo, gracias a lo cual fue posible la conclusión del mismo. esta agrupación. A simple vista, se tra. taba de formar y apoyar un órgano director, consultor y censor de la cultura y la educación. Las interrogantes que surgen en torno a este Instituto son innumerables, ¿cómo y bajo qué dirección funcionó?, y más allá de los objetivos planteados, ¿qué razón de ser tenía dicha institución en un periodo de transición como el que vivía México en los primeros años de independencia? Si no pretendía dedicarse a la enseñan$\mathrm{za}$, ¿tendría alguna relación con los esfuerzos que se hicieron para impulsar la instrucción pública? ¿cuál era ésta? Acaso, por el nombre que se le dio, ¿tuvo relación con los institutos literarios fundados en varios de los estados también en esos primeros años de re- 


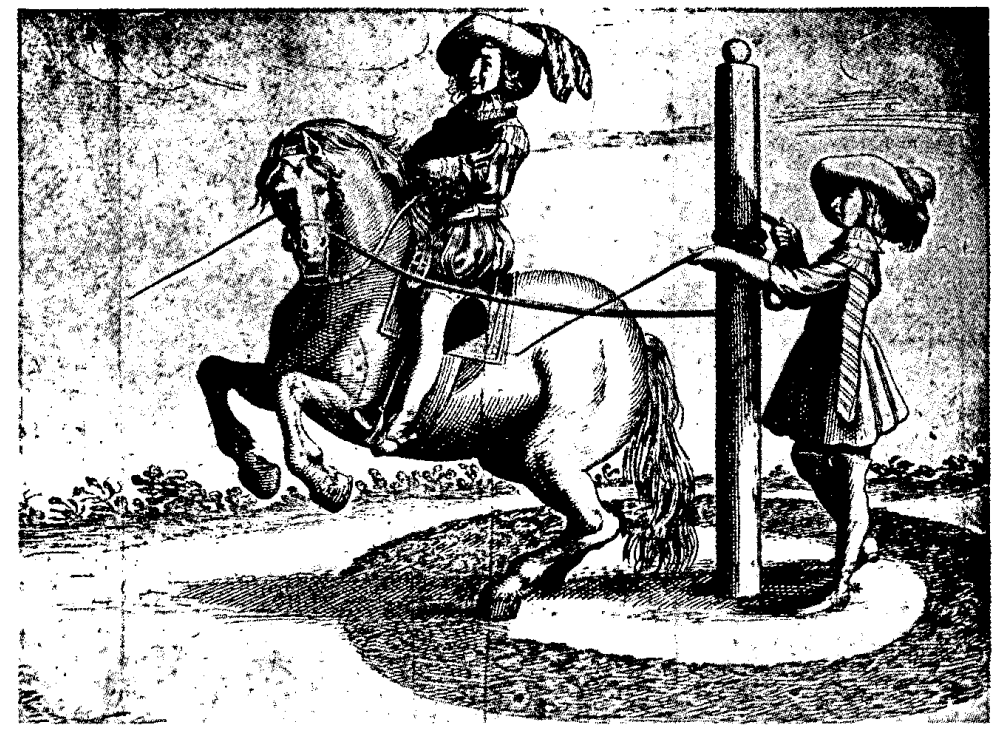

pública federal? ¿Tuvo algún significado dentro del proceso de construcción del Estado?

El interés de este trabajo es rescatar la historia del Instituto Nacional de Ciencias y Artes, creado en la ciudad de México en 1823 e institucionalizado en 1825, porque formó parte de una de las propuestas educativas, científicas y culturales más relevantes que se hicieron a lo largo de la primera década de la nación independiente, tendientes -sin la mención a esos términos- a secularizar la enseñanza. El análisis de sus objetivos y características, de los precedentes que lo inspiraron, de las condiciones políticas y sociales en que fue impulsado así como su fin y fusión en uno de los órganos administrativos considerados impor- tantes dentro de la proyectada estructura educativa, además de su posible vinculación con el surgimiento de los primeros institutos literarios, permitirá avanzar en la interpretación sobre su significado e importancia dentro del marco de transición de las instituciones de la colonia hacia el siglo XIX.

\section{LA SECULARIZACIÓN, UN PROBLEMA A REPLANTEAR}

El interés por estudiar el Instituto Nacional de Ciencias, Literatura y Artes se ha visto limitado, desde mi punto de vista, por la consideración de que fue otro más de los innumerables fracasos educativos que parecen permear la historia de la educación de México en la 
primera mitad del siglo xIx. La institución, de la que me ocuparé en las siguientes páginas, subsistió únicamente durante siete años, apenas tres de ellos en actividad. Por lo tanto, no existe una tradición historiográfica alrededor de la misma y, apenas, breves referencias. Es el caso de Juan de Dios Arias, quien en el México a través de los siglos describe en breves líneas la inauguración solemne. ${ }^{1}$ Algunos otros datos los proporciona la historiografia reciente en los trabajos de Carmen Ramos Escandón, Ernesto Meneses Morales y Stanley C. Green.2

El conocimiento del Instituto Nacional se ha inscrito pues, en una línea meramente anecdótica, por lo que no se ha considerado la importancia del proyecto del cual surgió, los objetivos bajo los que se planteó y su relación con el ambiente general de impulso a la instrucción pública que vivía Méxi. $c o$ en los primeros años de independencia. Elementos que, a mi parecer, dan las pautas para intentar enfocar el estudio de este Instituto y de los otros institutos que existieron en los estados, bajo una nueva perspectiva.

La secularización de la enseñanza, concepto utilizado por la historiografia sobre México para la primera mitad del siglo XIX, ${ }^{3}$ refiere el proceso de

\footnotetext{
${ }^{1}$ Riva Palacio, México, 1984, t. XII, pp. 138139.

2 Ramos, "Planes", 1972; Meneses, Tendencias, 1983; Green, Mexican, 1987, pp. 98-99. Este autor se apoya en las noticias vertidas por el Aguilla Mexicana, de junio de 1825.

3 Véanse Hale, Liberalismo, 1985; Costeloe Primera, 1983; Staples, "Panorama", 1985; Tanck, Educacion, 1984; Ramos "Planes", 1972; Meneses, Tendencias, 1983. Y más atrás, Bravo Ugarte, Educacion, 1966; Larroyo, Historia, 1981.
}

transición que se dio de la antigua organización de la educación a una nueva. El fenómeno tiene diversos aspectos, por ahora me interesa, en particular, aquel que se gestó en el plano administrativo. Las manifestaciones más generales de éste pueden centrarse en el paso al pleno control por parte del nuevo poder civil sobre las instituciones educativas, así como en el énfasis puesto en la formación de un sistema de instrucción pública que en México, como en otros lugares, no existía antes de la independencia.

La historiografia sobre educación ha avanzado acertadamente en apuntar la influencia que en los anteriores aspectos tuvo en México la reglamen. tación de Cádiz. ${ }^{4}$ En particular, desde una perspectiva legislativa ${ }^{5}$ y central, ${ }^{6}$ se ha puesto atención en el desarrollo de los planes educativos, el surgimien. to de una dirección de instrucción pública y la reforma educativa liberal de 1833. De todos estos aspectos, el único que se ha considerado como un fenómeno secularizador ha sido la reforma educativa liberal de 1833. Sin embargo, desde mi punto de vista, tanto los aspectos antes dichos como otros cabos sueltos que necesitan ama-

4 Larroyo, Historta, 1981.

5 La excepción es el importante trabajo de Tanck, Educactón, 1984, pues la autora trabajó sistemáticamente, documentación del Archivo del Ayuntamiento de México aunque sólo para el caso de la educación primaria en la ciudad de México.

6 En el sentido de que se comprenden acciones para el Distrito Federal y Territorios pues, debe recordarse, durante la vigencia de la primera república federal así ocurrió y es la década que más se ha estudiado en la historiografía sobre educación. 
rrarse formaron parte del mismo proceso. En ese panorama pues, deben incluirse los institutos literarios fundados en los estados durante la tercera década del siglo XIX, la reforma de los antiguos colegios y de la Universidad y también, establecimientos como el Instituto Nacional, pese a su relativo éxito.

Entonces parece conveniente que, para poder entender el proceso de transición de la antigua a la nueva enseñanza, de su secularización, se requiere replantear el problema: un primer paso será partir del conocimiento de cada una de esas nuevas instituciones en particular y, a continuación, importa situarlas en función del papel que jugarian dentro del conjunto que se buscaba formar. Además, si dicho proceso -como lo ha demostrado en algunos aspectos la historiografia, en especial para la reforma educativa de 1833- se inició a partir de los cambios ordenados en la reglamentación emanada de las Cortes de Cádiz, ${ }^{7}$ los institutos deberán enfocarse a partir de esos mismos orígenes y bajo la perspectiva de la secularización.

Las fuentes empleadas para la elaboración de este trabajo proceden del Fondo Lafragua de la Biblioteca y Hemeroteca Nacional, y del AGN, Ramo Justicia e Instrucción Pública. ${ }^{8}$ Se trata de un folleto que incluye: el discurso inaugural pronunciado por Andrés Quintana Roo; listas de socios y corresponsales en los estados y en el extranjero, pues en el Instituto existían esas

7 Tanck, Educacion, 1984, Meneses, Tendenctas, 1983.

8 Vol. $x$, ff. 14-31. categorías, así como las composiciones poéticas preparadas para la ocasión solemne de su inauguración. ${ }^{9} \mathrm{La}$ legislación y las Memorias del ramo hasta 1833 también recogieron parte de una historia hasta ahora sin relevancia, ${ }^{10}$ y además, contamos con algunos documentos oficiales sobre la aprobación e instalación del Instituto.

EL TRASFONDO GADITANO: UN PROGRAMA ORGÁNICO

En 1826, después de la instalación del Instituto Nacional, la noticia publicada en Aguila Mexicana se refírió a "la consistencia y celebridad [del] Instituto de Francia, ${ }^{11}$ establecido en París con el objeto grandioso de perfeccionar las ciencias y las artes [...]" y que, de seguir sus huellas, [el nacional] llegaría a ocupar, un lugar célebre "en la república de las ciencias y de las artes en el nuevo mundon. ${ }^{12}$ Esta alusión revela las ideas de mayor influencia en ese momento, para la construcción de un sistema educativo en México. Sin embargo, a pesar de lo anterior, las ideas rectoras provenían directamente de España. Sin duda, debido a la independencia, que tenía tan poco tiempo de haber-

\footnotetext{
9 Memorias, 1826.

10 Dublán y Lozano, Legislación, vol. n,

11 El Instituto de Francia se estableció en París en 1795 por la ley Daunou de 25 de octubre. Estaba dividido en tres clases: ciencias físicas y matemáticas, ciencias morales y políticas, literatura y artes. Cumplía una doble función: como Academia y como lo que en la actualidad es una institución nacional de investigación científica. Mialaret, y Vial, Histoire, 1981, pp. 321.322.

${ }^{12}$ Aguila Mexicana, 5 de abril de 1826, p. 1.
} 1887. 
se consumado, y a la natural aversión que habría en esos momentos a reconocer de forma abierta la influencia gaditana, se trató de dar la idea de que Francia había sido la matriz intelectual de los planes educativos mexicanos. Por lo demás, cabe reconocer que en el fondo así era, pues de Francia tomó Manuel José Quintana ${ }^{13}$ las ideas fundamentales para presentar su proyecto de educación ante las Cortes de Cádiz en 1814, mismos que después pasaron prácticamente íntegras al Reglamento de Cádiz de 1821.

En efecto, en los proyectos educativos franceses y españoles de fines del siglo XVIII y principios del XIX, se pensó en crear un sistema centralizado de educación. En Francia se discutieron dos planes educativos presentados, uno por Talleyrand-Perigord [1791], y el otro por Condorcet [1792].$^{14} \mathrm{Am}$ bos personajes propusieron una estructura educativa nacional cuyos principios básicos serían libertad, igualdad, gratuidad y universalidad, si bien en cada caso había matices que los diferenciaban. Una institución central sería el eje y estaría dedicada a dirigir, promover y sancionar las ciencias, la literatura y las artes así como a vigilar la instrucción pública; Talleyrand-Perigord lo llamó expresamente Instituto Nacional, mientras que Condorcet ha-

13 Poeta y político liberal español (1772. 1857), participó en la administración en innumerables ocasiones, en especial como censor de teatros y director de la dirección de instrucción pública. La postura política defendida le causó no pocos encierros y destierros. Su obra literaria y periodística es abundante. Véase Quintana, Obras, 1882 y Enciclopedia, 1976.

14 Valle López, "Huella", 1990, pp. 141-171; Condorcet, Informe, 1992, pp. 125-213. bló de una Sociedad Nacional de las Ciencias y las Artes. ${ }^{15} \mathrm{Tal}$ órgano, que no se dedicaría a la enseñanza, estaría por encima de todos los establecimientos cuya función estribaría en dedicarse a ella. Estas ideas pasaron prontamente a España. Así, en 1809, en uno de los más importantes textos que sobre el tema escribió Gaspar Melchor de Jovellanos, las "Bases para la formación de un plan general de Instrucción Pública", el ilustrado español proponía para "el arreglo de la enseñanza": su gratuidad, uniformidad, e impartición en castellano; además, la formación de una junta encargada de dirigir a los institutos y universidades de las principales ciudades del reino, la creación de cuatro academias dedicadas al cultivo de las humanidades, letras castellanas e historia nacional, a las humanidades clásicas y a las ciencias especulativas y prácticas. ${ }^{16}$ Los términos de la propuesta seguían las tendencias de los pedagogos franceses pero mantenían diferencias, pues Jovellanos dividía las funciones de inspección de la instrucción pública y de promoción y sanción de las ciencias para ser encomendadas a órganos distintos.

En el marco de tales precedentes, las Cortes de Cádiz procedieron, en 1812 , a decretar algunas medidas con la finalidad de formar un sistema educativo, pues se les habían concedido

15 Condorcet, Informe, 1992, pp. 170-179. Las funciones que asignó el autor a la Sociedad Nacional eran "para dirigir y vigilar los establecimientos de instrucción, para ocuparse en el perfeccionamiento de las ciencias y de las artes, para recoger, estimular y esparcir los descubrimientos útiles."

${ }^{16}$ Jovellanos, "Bases", 1951, p. 271. 
facultades para la reorganización de la instrucción pública por medio de planes. ${ }^{17}$ Entonces ordenaron la creación de una Dirección General de Estudios que inspeccionara la enseñanza (art. 369), y la elaboración de un plan uniforme para todo el reino. De tal modo, un año después, el 18de junio de 1813 , el Ministerio de Gobernación de la península encomendó a Manuel José Quintana la formación de una propuesta de educación que presentó ante las Cortes en $1814 .^{18}$ El sistema de instrucción pública, planteado por la Comisión encabezada por Quintana para "el arreglo de la educación literaria", partía también de cuatro bases generales: la universalidad, gratuidad, uniformidad y libertad de la enseñanza: la división de la misma en tres clases: primera, segunda y tercera; la existencia de escuelas de primeras letras, universidades de provincia para la segunda enseñanza y universidades mayores; la creación de una dirección general que supervisara los estudios y, por fín, como "último grado de instrucción de los cultivadores de la ciencia", el proyecto contemplaba una Academia Nacional que estaría dividida en tres clases, de acuerdo con la división más general de las ciencias. Además, consideraba la dotación de fondos para la instrucción pública. ${ }^{19}$ Esto es, se trataba de una estructura educativa centralizada y jerárquica.

17 Dublán y Lozano, Legislactón, vol. I, 1887, p. 355; Tanck, "Cortes", 1979, pp. 6-7 y Almada, "Reforma", 1967, pp. 104-106.

18 Historia, 1979 , pp. 353-376.

19 Quintana, "Informe", 1946. Véase Mérida, "Concepto", 1990, p. 137.
Para los reinos y provincias de ultramar, el informe proponía la aplicación del proyecto conforme a las condiciones de la localidad y distancias de "aquellos países".

Debido al regreso de Fernando VII y por tanto, a la disolución de las Cortes, no llegó a sancionarse el anterior proyecto. Cuando la política dio un nuevo giro y se reinstaló el gobierno liberal en España, hubo otra oportunidad de poner en práctica los cambios educativos propuestos. En 1821 fue nombra. da una Comisión para formular el Reglamento de Instrucción Pública. En él fueron retomados, en términos generales, los planteamientos del presentado por Quintana en 1814. Por cierto, en el segundo grupo participó directa. mente, en calidad de diputado a Cortes por México, Pablo de la Llave, entonces residente en España. Por otra parte, dicha legislación, una vez sancionada, todavía fue enviada a México y, a diferencia del Informe, detallaba con gran precisión su aplicación en todos los reinos y provincias de ultramar, como se verá a continuación para el caso de México.

El Reglamento, que proponía pues la formación de un sistema de instrucción pública centralizado, dictaba para la Nueva España la fundación de universidades de provincia - de segunda enseñanza- y la existencia de una cen. tral, papel que correspondería a la Real Universidad de México. Tanto unas como la otra, estarían adscritas a una subdirección de instrucción pública, también en México, dependientes todas de una Dirección Central con sede en España, y se mantendría en comunicación con una Academia Nacio- 
nal. ${ }^{20}$ Esta compleja propuesta, a todas luces inviable por la nueva situación independiente de México, sin embargo, no se perdió, antes bien, se mantuvo subyacente en las posteriores propuestas y planes educativos que se formularon entre 1823 y $1833 .^{21}$

A la fe puesta por los principales políticos mexicanos en el importante papel de legitimación que debía jugar la instrucción pública en el nuevo régimen de gobierno, expresada por personajes como José María Luis Mora $^{22}$ y Lucas Alamán, ${ }^{23}$ se agregó la acción. Así que para conseguir tales objetivos de ilustrar al pueblo resultaba indispensable organizar la instrucción pública. A esa tarea pues, se abocaron, con mayor o menor éxito, los diferen-

${ }^{20}$ Historia, 1979, pp. 49-67.

21 El Reglamento fue dado a conocer en España el 29 de junio de 1821 y se recibió en México cuando se había consumado la independencia.

22 Mora señalaba: "Para entender la Constitución y las leyes es indispensable saber leer; para pesar las razones alegadas en la tribuna nacional, sea para la formación o reforma de la una y las otras, se requiere tener algunos conocimientos generales, a lo menos haber adquirido algunas reglas en el arte de pensar, para sujetar el juicio; de lo contrario, no es posible que las reglas morales que deben servir de guia al hombre social tengan todo el buen resultado que desean los filósofos y legisladores". Mora, "Proposición", 1967, p. 60.

23 A lamán también escribia: "Sin instrucción no hay libertad, y cuanto más difundida esté aquélla, tanto más sólidamente cimentada se hallará ésta” pues "el [nuevo) régimen debe apoyarse sobre la base sólida de la ilustración general[...] el gobierno liberal debe ser sostenido por la opinión pública -sanos principios- ¿Cómo podrian seguirse éstos si no se velase sobre la educación y primera instrucción de la juventud?" "Educación Pública" en periódico Sabattna Universal, 1828, en Staples, Educar, 1985, pp. 25-26. tes gobiernos que existieron a lo largo del decenio 1823 a 1833. Por el momento, me ocuparé del que parece ser el primero de ellos.

\section{PIEZAS DE UN ROMPECABEZAS QUE NUNCA SE ARMÓ}

En 1823, después de la caída de Agus. tín de Iturbide, se inició un debate acerca de la forma de gobierno que convenía al naciente país. ${ }^{24}$ Existía consenso en el régimen republicano, pero de. sacuerdo en la forma central o federal. La creciente autonomía de las regiones pugnaba fuertemente por el federalismo, ${ }^{25}$ pero las voces por el centralismo también se hacían escuchar.

En el marco de acciones emprendidas para conciliar los intereses federa. listas en pugna, una Comisión ${ }^{26}$ inte. grada por Fray Servando Teresa de Mier, ${ }^{27}$ José del Valle, ${ }^{28}$ Juan de Dios

${ }^{24}$ Anna, Imperio, 1991.

25 Hamnett, "Factores", 1984, pp. 305-317.

26 Una posible vertiente en el seguimiento del problema planteado en el presente trabajo sería el análisis prosopográfico de los distintos personajes involucrados en las comisiones que se formaron a lo largo del periodo. En particular, en lo tocante a sus tendencias políticas, su perfil socioeconómico o los puestos que desempeñaban, para poder obtener otro tipo de conclusio nes. Por el momento, solamente se anotan algunos datos biográficos de aquellos que son menos conocidos y que fueron localizados. Aquí se aplica en parte ese proceso para los que fueron socios del Instituto Nacional, en especial si se tiene certeza de que participaron en êl activamente, agregando, si es el caso, la vinculación que tuvieron con los institutos literarios provinciales.

${ }^{27}$ Rodriguez, "Intellectuals", 1991, pp. 63-74.

28 (1780-1834). Político guatemalteco, graduado en ambos derechos; fue diputado a Cortes por León, Nicaragua. Fundó en 1820 El amt. 
Mayorga, ${ }^{29}$ José Mariano Marín, Lorenzo de Zavala, José María Bocanegra, ${ }^{30}$ entre otros, presentó el 28 de mayo de 1823 un documento titulado Plan de la Constitución Política de la República. En éste, de acuerdo con el art. $1^{\circ}$, la forma de gobierno, emanada de la soberanía de la nación, era el de ser "una república representativa y federal" ${ }^{31}$ A pesar de lo cual, para aquellos representantes de algunas provincias de exaltado federalismo, la moderada autonomía que se concedía a los estados no les resultó satisfactoria pues se identificaron puntos de fuerte centralismo, en el mencionado Plan.

go de la patria, portavoz de los moderados guatemaltecos. Al adherirse Guatemala al imperio, Valle actuó como diputado en el Congreso (1822), pero al poco tiempo se separó de Iturbide. Fue ministro de Relaciones Exteriores (23 de febrero a 31 de marzo de 1823). Firmó la Constitución de 1824, Diccionario, 1986.

29 Murió en 1837, guatemalteco; diputado por esa provincia al primer Congreso Constituyente de México; fue preso por orden de Iturbide y después volvió a ocupar su curul. Permaneció en México hasta 1827 . Zavala lo califica como liberal.

${ }^{30}$ (1787-1862) Abogado y político, nació en la I.abor de la Troje, Aguascalientes. Abogado de la Real Audiencia y miembro del Colegio de abogados; fue diputado por su provincia al primer Congreso General Constituyente y al segundo Congreso (1827-1828); también ministro del Su. premo Tribunal de Justicia. Elegido por Vicente Guerrero, fungió como presidente interino del 18 al 23 de diciembre de 1829 , cesando por causa del Pronunciamiento de Jalapa. Durante el régimen liberal participó como ministro de Hacienda ( 26 de abril al 23 de diciembre de 1833) y de Relaciones Exteriores en dos ocasiones (27 de octubre a 6 de noviembre de $1837 ; 18$ de noviembre de 1841 a 24 de julio de 1844). Autor de Memorias para la Historia del México independiente (1822-1846). Diccionario, 1986.

${ }^{31}$ Plan, 1975, pp. 147-152.
En el caso de la educación, por ejemplo, el artículo $6^{\circ}$ señalaba el objetivo de establecer institutos públicos: uno central, en el lugar que designe el cuerpo legislativo, y otro local en cada provincia. El papel del nacional estaría en vigilar la observación del plan general de educación formado por el cuerpo legislativo; hacer los reglamentos e instrucciones precisos para su cumplimiento y circular a los institutos provinciales las leyes y decretos relativos a la instrucción pública que debía comunicarle el cuerpo legislativo; además, determinar los métodos de enseñanza y su variación según los progresos de la razón, y proteger a los establecimientos que fomenten las artes y las ciencias. Una más de sus atribuciones estaría en intercambiar correspondencia con las Academias de las naciones más ilustradas para reunir los documentos útiles, comunicarlos a los institutos de cada provincia y ordenar los ensayos o experimentos que interesen más al bien de la nación. Esta institución se compondría de profesores instruidos en cuatro clases de ciencias: físicas, exactas, morales y políticas, y serían nombrados por el cuerpo legislativo. En suma, el plan establece que la legislatura gobernaría a la institución nacional y ésta, a su vez, mantendría bajo su cuidado a los establecimientos de provincia. El papel de éstos, como también lo manifiesta el decreto, sería el de "cuidar el cumplimiento del plan de educación en su provincia respectiva y procurar la ilustración de los ciudadanos; así como enviar cada año al instituto nacional las memorias respectivas sobre el estado de la instrucción públi- 
ca y las recomendaciones pertinentes parasuprogreso". ${ }^{32}$ Esto es, procurar la ilustración equivalía a que los ins. titutos provinciales, a diferencia del nacional, se encargarían de impartir enseñanza. Por lo demás, en ellos se introducirían los conocimientos que sustentaban las nuevas ideas políticas, así como las artes, forma utilitaria derivada de las corrientes de pensamiento en boga.

El proyecto educativo, como puede apreciarse, proponía la creación de un sistema centralizado, basado en un establecimiento nacional, más otros provinciales. En líneas generales, si bien orientando las características del sistema a las condiciones políticas de México, se seguía el Reglamento de Cádiz básicamente en dos aspectos: el primero, el funcionamiento de un Instituto Nacional, con sede en la capital de la república, que fuera el centro rector de las ciencias, literatura y artes, además de tener la función de inspeccionar la enseñanza; el segundo, la creación de institutos provinciales subordinados al nacional.

Por otra parte, conviene detenerse en la designación de instituto que se dio en México a las nuevas instituciones, en lugar de universidad y academia, como lo proponía la reglamentación española. En ésta, en 1814, Quintana manifestó acerca del nombre "universidades de provincia": "denominación que nos ha parecido conservar en obsequio de su antigüedad venerable ${ }^{n}$; mientras que el término "instituto" lo utilizaba indistintamente para referirse genéricamente a los es-

$32 \mathrm{lbid}$. Las cursivas son mías. tablecimientos de instrucción pública, en particular los dedicados a la segunda y tercera enseñanza. En cam. bio, en México, la preferencia por el nombre de institutos obedeció a la batalla que se entabló, a partir de la independencia, contra la corporación universitaria y que llevó a realizar acciones radicales más allá de evitar un nombre: por ejemplo, a la supresión de la Universidad de México en 1833.

Hasta aquí resulta claro que en la república recién independizada, la preocupación por estructurar un sistema de instrucción pública centralizado nació de la presencia subyacente de la reglamentación de Cádiz y de la experiencia adquirida por los políticos mexicanos que estuvieron ahí.

A pesar de que resultó imposible realizar el proyecto presentado en el Plan de la Constitución de 1823, hubo otras medidas prácticas con objetivos semejantes que se desarrollaron paralelamente. Así, en ese mismo año, el gobierno ordenó a los Ministerios de Relaciones Interiores y Exteriores, y de Justicia la formulación de un plan general de instrucción pública. ${ }^{33}$ Para ello se pidió a los diferentes establecimientos educativos el envío de informes sobre las condiciones y necesida. des que guardaban cada uno de los mismos. ${ }^{34}$ Entre los recibidos, se cuentan el del Colegio de San Ildefonso,

33 Tanck, "Cortes", 1979, p. 7.

34 "Solicitud de informes sobre los establecimientos educativos y científicos que gira la sección de fomento e instrucción pública a todos los rectores y directores de establecimientos y a los jefes políticos superiores de las provincias" en Mora, Obras completas, 1986, vol. 1, Obra Polittca, pp. 50-54. 
enviado en abril de $1823^{35}$-suscrito por José María Luis Mora-y el del Convento de los Carmelitas, ${ }^{36}$ remitido por su provincial. Para examinar "los informes [que] se han ido sucesivamente recibiendo de todos los establecimientos de esta especie existentes ${ }^{n 37}$ y llegar a la elaboración de una propuesta para "arreglar" la instrucción pública se formó una Comisión de personas "conocidas y apreciadas por la variedad y profundidad de su instrucción".

La comisión quedó integrada por Jacobo Villaurrutia, ${ }^{38}$ Andrés del Río, ${ }^{39}$ José Nicolás Maniau y Torque.

35 El informe de ese colegio se encuentra en Mora, 1986, Obras, pp. 29-49.

$36 \mathrm{Ibid}$.

37 Véase Alamán, Memoria, 1823, p. 88.

38 (1757-1833) Originario de Santo Domingo, estudió en el Seminario de México para dedicarse a la carrera eclesiástica. En Madrid obtuvo su título de abogado; retornó a México en 1804 y fundó, junto con Carlos María de Bustamante, el primer periódico cotidiano de la A mérica española, el Diario de México. En $1807 \mathrm{pu}$ blicó sus artículos sobre un Sistema de Instrucción Pública con ideas reformistas. Miembro de los Guadalupes, participó en las agitaciones políticas de 1808 , por lo que tuvo que salir de la Nueva España con rumbo a Europa. Después de la independencia, regresó a México donde fue presidente de la Suprema Corte de Justicia. Guedea, Btusca, 1992; Diccionario, 1986.

39 (1764-1849) Mineralogista, graduado ba. chiller por la Universidad de Alcalá de Henares en 1780; el gobierno español lo envió a la Academia de Minas de A lmadén; nombrado catedrático del Colegio de Minería de México, llegó a la Nueva España en 1795, abriendo el primer curso de mineralogía ofrecido aquí. Fue diputado a Cortes en 1820 y se pronunció a favor de la independencia; regresa a México en 1824 y en 1829 sale a los Estados Unidos al ser expulsados los españoles, aunque era de los exceptuados. Retornó en 1835. Diccionario, 1986. mada, ${ }^{40}$ José Benito Guerra, ${ }^{41}$ R. P. Antonio Serrano, ${ }^{42}$ Juan de Balenchana $y$ Vicente Cervantes, ${ }^{43}$ y concluyó el Plan en diciembre de 1823. Este grupo, por lo que puede observarse, guardaba un perfil bastante distinto a aquel que elaboró el Plan de la Constitución, sin embargo, las ideas que manejaron

40 (1775-?) Nació en Jalapa, Ver., Dr. en Teología llegó a ser juez eclesiástico de Chilapa, canónigo de la catedral de Puebla y prebendado de la catedral de México. Destacó como orador sagrado y publicó algunas oraciones fúnebres, entre ellas, la dicha en latín en las exequias de Carlos IV, impresa en México en 1820. Dicctonarto, 1986.

41 (1777-?) Político, nació en Querétaro, fue miembro distinguido de los Guadalupes, participó en la compra y envío de una imprenta a Ignacio López Rayón en abril de 1812; fue aprehendido y, poco después, puesto en libertad. En 1820 fue electo regidor y síndico constitucional para el Ayuntamiento de la Ciudad de México y en septiembre lo fue para diputado a Cortes, aunque no fue a España. Formó parte de la Diputación Provincial en 1823 y 1824 y también del. Congreso del estado de México. Guedea, Busca, 1992; Diccionario, 1986.

42 (?-1833) Cirujano español, llegó a la Nueva España en 1794 con el cargo de segundo catedrático y director de la Escuela de Cirugía de Méxi. co, cargo que ocupó hasta 1827. Dio un gran impulso a la cirugía en México y buscó elevar la categoría social de los cirujanos; ayudó a la introducción y propagación de la vacuna contra la viruela. Fue cirujano del hospital de San Andrés y alcalde examinador del Real Tribunal del Protomedicato. Diccionario, 1986.

43 (1755-1829) Botánico español. Nació en Extremadura; participó en diferentes instituciones científicas en las cuales demostró su capacidad, por lo cual, Carlos III lo nombró miembro de la expedición botánica a Nueva España, a donde llegó en 1787. Nombrado profesor de botánica en la Universidad de México, funđó en unión de Sessé, el Jardín Botánico, del cual quedó como director en 1802. Durante 18 años fue director del Hospital de San Andrés y escribió diversas obras sobre botánica. Dicclonarto, 1986. 


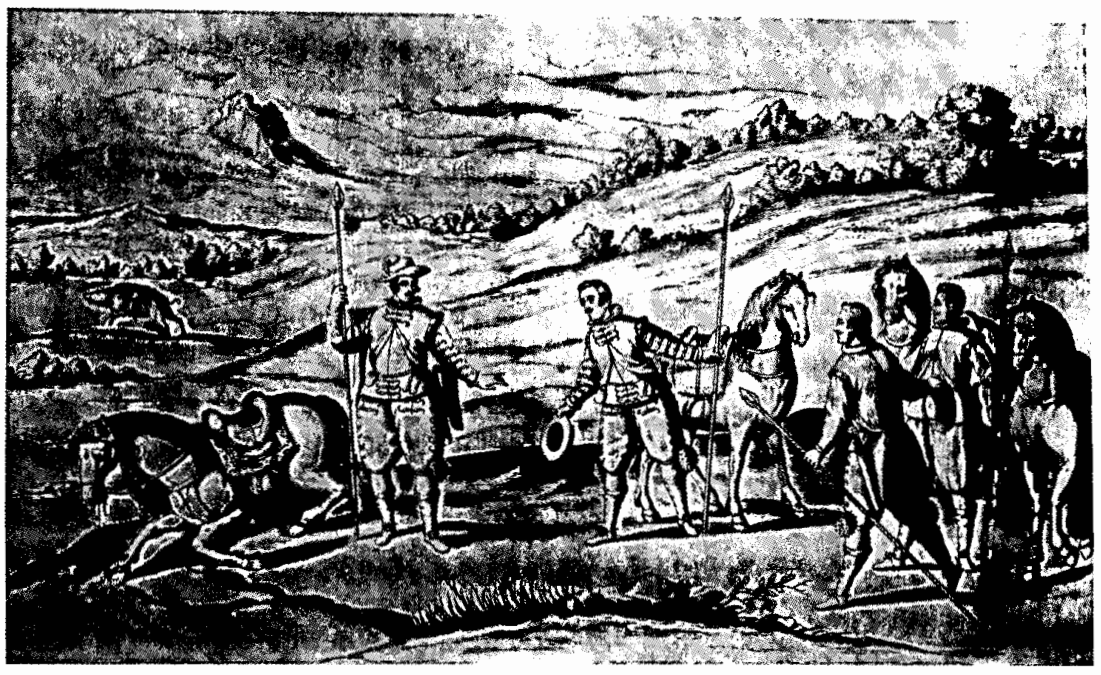

en la elaboración de su proyecto no diferían sustancialmente.

El proyecto fue presentado por Alamán, entonces ministro de Relaciones Interiores y Exteriores, bajo el título de "Proyecto de reglamento general de Instrucción Pública" ${ }^{44}$ y proponía: la gratuidad y uniformidad de la instrucción costeada por el gobierno - tendría métodos y textos iguales-; establecía la creación de una Dirección General a cargo del Congreso, encargada de la organización de la educación y del ma. nejo de todos los fondos destinados a ese ramo. Para las provincias, proponía la existencia de direcciones locales similares a la nacional y subordinadas

44 Citado en nota a pie de página por Green, Mexican, 1987, p. 253. a ésta. ${ }^{45}$ En el proyecto se dividía la instrucción en primaria, secundaria y terciaria, de la cual se harian responsa. bles, respectivamente, los ayuntamientos, colegios y universidades. Además, se buscaría reunir a los profesores en Academias. Las similitudes y el manejo de algunos términos con respecto al Plan de la Constitución, de mayo de 1823 , saltan a la vista. Por lo demás, la propia Comisión, en voz de Villaurrutia, reconoció las bases gaditanas que lo guiaban:

las mismas en sustancia que las del proyecto de arreglo general de enseñanza pública presentado en 1814 a las primeras Cortes Ordinarias, adoptado en las

45 Ramos, "Planes", 1972, pp. 25-29. 
luminarias discusiones que comenzaron en octubre de 1820 y acabaron en 1821 , en que se decretó y se mandó poner en ejecución. 46

De cualquier forma, las circunstancias políticas en las que se veía envuelta la república no permitieron la implantación de estos proyectos. En especial el primero, porque además de ser apenas una propuesta, no tuvo ninguna viabilidad al consolidarse el proceso hacía la federación y el establecimiento final de una república federal. ${ }^{47}$ Pues, como es sabido, a principios del mes de junio de 1823 empezó a darse el movimiento de instalación de Congresos Estatales: el 16 de junio, Nueva Galicia fue erigida por su Diputación en estado libre de Jalisco y el 14 de septiembre quedó instalado su Congreso; a éste siguieron Oaxaca, Yucatán y Zacatecas (6 de julio, 20 de agosto y 19 de octubre) y se extendió a otras provincias. De tal forma, el 12 de junio de 1823 el Congreso emitió un voto por el sistema federal y el decreto de convocatoria a un nuevo Congreso para constituir a la nación.

De acuerdo con el Acta Constitutiva y la Constitución de 1824, los estados fueron declarados "independientes, libres y soberanos, en lo que exclusivamente toque a su administración y gobierno interior...". 48 Por lo tanto, los estados quedaron en libertad de formar sus propias constituciones. En lo

46 Archivo General de la Nación (AGN), Gobernación, caja 4, exp. 18. Citado por Tanck, "Cortes", 1979 , p. 7.

47 Costeloe, Primera, 1983, pp. 11.33; Green, Mexican, 1987, cap. II, pp. 31-51; Dublán y Lozano, Legislación, 1887, vol. u, p. 651. 48 Tena Ramirez, Leyes, 1975, art. 6. concerniente a la educación, el artículo 50 especificaba el derecho que tenían aquéllos para impulsarla. 49

Así pues, el primer intento de formar un sistema centralizado de instrucción pública quedó solamente en el papel. Sin embargo, si no fue posible entonces articular las instituciones, subyacía la posibilidad, gracias al régimen de gobierno federal, de su instrumentación tanto en la capital como en las provincias; en éstas prevalecería como una pauta más de su fortalecimiento regional.

\section{EL INSTI'UUTO NACIONAL DE CIENCIAS Y ARTES}

En la capital, de acuerdo con comentarios de Manuel Díez de Bonilla, una institución bajo el titulo de Instituto de Ciencias, Literatura y Artes comenzó a funcionar a partir de 1823, pero le hacía falta el respaldo del gobierno para, como era firme la creencia en aquellos años, "producir las mayores ventajas a los conocimientos útiles de una nación que pueden hacer este tipo de establecimientos" 50

De tal forma, el 25 de marzo de 1825 , Juan José Espinosa de los Monteros envió para su aprobación el Proyecto de Reglamento del Instituto, ${ }^{51}$ a la Prime. ra Secretaría de Estado a cargo de Lucas Alamán. La respuesta del gobierno

49 Ibid., p. 174.

50 Aguila Moricana, 5 de abril de 1826, p. 1.

51 "Proyecto de Reglamento del Instituto de Ciencias, Literatura y Artes presentado por Juan José Espinosa de los Monteros", AGN, Ramo Justicia e Instrucción Pública, vol. x, ff. 14-15, 29 de marzo de 1825. 
no se hizo esperar. La aprobación fue dada el 16 de abril de 1825 y se le otorgó también el título de nacional; además se le asignamon 3000 pesos para su gasto. ${ }^{52}$ ¿Era posible aceptar el antiguo planteamiento de una institución central y nacional que se encargara de dirigir el desarrollo de las ciencias y las artes? ¿En qué sentido y para qué era nacional? La soberanía de la nueva nación, de acuerdo al artículo 6 de la Constitución federal de 1824, quedaba compartida entre la nación y los estados. ${ }^{53}$ De tal forma, los hilos para mantener la unión de la nación se tendrían que establecer. Y esto trató de aplicarse en varios planos. ${ }^{54} \mathrm{La}$ existencia de una institución nacional que dirigiera, promoviera, sancionara y calificara la cultura y las artes, era, a mi parecer, una medida que, en ese plano, trataría de sostener la unión.

El establecimiento formal del Instituto Nacional se realizó un año después, en la capital de la federación. En efecto, el 2 de abril de 1826 , en un acto por demás solemne, organizado por su Junta Directiva en sesión de 17 de febrero, se inauguró el Instituto en el Aula Mayor de la Universidad de México, ${ }^{55}$ que se encontraba adornada e ilu-

52 Documento de la Comisión de Instrucción Pública y Hacienda aprobando el Instituto de Ciencias, Literatura y Artes con el título de nacional. 11 de abril de 1825 . AGN, Ramo Justicia e Instrucción Pública, vol. x, ff. 18v.

53 Véase Rodríguez, "Independencia”, 1993.

${ }^{54}$ En el económico, por ejemplo, se estableció legislativamente el pago de un contingente a bs estados, el cual casi nunca fue entregado.

${ }^{55}$ Aguila Mexicana, México, miércoles 5 de abril de 1826, año $\mathrm{II}$, núm. 356 , p. 1; Andrés Quintana Roo, "Discurso inaugural del Instituto de ciencias, literatura y artes ${ }^{n}$ en Memortas, 1826, p. 21. minada adecuadamente para la ocasión, y ante la presencia de gran número de socios. ${ }^{56}$

En la ceremonia, el secretario de la Junta directiva del Instituto leyó, en primer lugar, los nombres de todos los posibles socios, que sumaban en total 50 de número, 39 correspondientes a 16 estados, 23 del extranjero, tanto de Europa como de diferentes regiones de América; y 82 honorarios. ${ }^{77}$ Estas listas, por otra parte, lejos de sorprender, confirman la leve distancia que separaba las diversas tendencias de los actores políticos en estos iniciales años del México independiente. Proborbones y republicanos, escoceses o yorkinos, federal istas y centralistas se encontraban involucrados, en apariencia, para apoyar y participar en la consolidación del Instituto. De tal forma, encontramos reunidos como socios, en las listas de la incipiente institución que buscaba controlar el conocimiento científico y artístico en general, a personajes tan disímbolos como Guadalupe Victoria, Lucas Ala. mán, Lorenzo de Zavala, Francisco García Salinas, ${ }^{58}$ Florencio del Casti.

56 Agutla Mexicana, 5 de abril de 1826; Riva Palacio, México, 1984, p. 138.

57 Memortas, 1826 , pp. 1-6.

58 Francisco García Salinas nació en la $\mathrm{Ha}$ cienda de la labor de Santa Gertrudis (hoy Rancho de "La Gavia"), inmediata a la ciudad de Jerez (hoy Jerez de García Salinas), el 30 de noviembre de 1786. Realizó estudios en el Seminario Conciliar de Guadalajara y después radicó en Zacatecas dedicándose a negociaciones mineras. Representó a su estado como senador y diputado; fue ministro de Hacienda. Suplió al gobernador José María García Rojas el último año de la gestión de éste y posteriormente fue clecto gobernador constitucional. Durante su guberna. tura impulsó la creación de un establecimiento 
1lo, 59 Manuel Gómez Pedraza, Vicente Guerrero y muchos otros. 60

Para la conexión con el extranjero se había pensado en corresponsales como el representante diplomático de los Estados Unidos en México, Joel. R. Poinsett, el libertador Simón Bolívar, el liberal español exiliado en Inglaterra José Blanco White y el sabio alemán, barón de Humboldt. ¿Cómo fueron escogidos? ¿Cuántos participaban realmente? La certeza existe respecto a Alamán, Quintana Roo, José María Tornel y Mendivil, ${ }^{61}$ Juan Wenceslao de la Barquera, ${ }^{62}$ Francisco Sánchez de Tagle, ${ }^{63}$ José

de enseñanza científica y literaria en la ciudad de Jerez (1832), que después pasó a ser el Instituto Literario. Murió el 2 de diciembre de 1841. Véase Vidal, "Francisco", 1986, pp. 11-34.

59 (?-1834) Sacerdote y político; originario de Costa Rica, se ordenó en el Seminario de León, Nicaragua, donde enseñó filosofía, y del que liegó a ser vicerrector. Participó en las Cortes de Cádiz (1811-1814). Canónigo de la Catedral de Oaxaca desde 1814. Presidente de la junta diocesana convocada por Iturbide en 1822; diputado por Costa Rica al Primer Constituyente de México fue nombrado miembro del Consejo de Esta. do. Participó en la 2* Legislatura oaxaqueña, de 1a que fue presidente. Fue uno de los fundado res, director y profesor de leyes del Instituto de Ciencia y Artes de Oaxaca. Dtccionario, 1986.

60 Véase el anexo al final.

61 José María Tornel nació en Vetacruz en 1789. A partir de 1813 se incorporó a las fuerzas insurgentes y en 1821 se adhirióal Plan de Iguala poniéndose a las órdenes de Santa Anna, a quien sirvió entonces como secretario. Fue diputado federal, gobernador del Distrito, ministro de Mé. xico en Estados Unidos, oficial mayor de Guerra y Marina y ministro de esta cartera cada vez que Santa A nna ocupaba la presidencia de la república. Véase Dicctonario, 1986.

62 Nació en Querétaro (1779); realizó estudios de jurisprudencia en el Colegio de San Ildefonso de México; recibió la licencia de abogado en 1809; se dio a conocer en el Dtarlo de México que dirigió de 1806 a 1810; participó en el mo-
María Heredia, ${ }^{64}$ Manuel Diez de Boni$11 a^{65}$ y Mariano Michelena. ${ }^{66}$

vimiento independiente burlando la censura de la Inquisición y del gobierno virreinal. Publicó diversos periódicos; formó parte de la Sociedad Secreta de los Guadalupes; fue redactor de la Gaceta Offctal. En 1825 promovió en unión de otros personajes, la celebración del día 16 de septiembre. Desempeñó diversos cargos públicos. Se reconoce su importante labor educativa. Guedea, Busca, 1992, pp. 376.377.

63 Nació en Valladolid (1782); emparentado con la familia Fagoaga; participó en el Ayunta. miento de la ciudad de México (regidor perpe. tuo de 1805.1812 y 1815 a 1820) (regidor constitucional de 1813-1814 y 1820-1821); bachiller en teología y filosofia; propietario; diputado a Cortes (1814), participó también en la Junta Gubernativa (1821-1822); fue firmante del Acta de Independencia. Guedea, Busca, 1992.

64 (1803-1839). Originario de Santiago de Cuba, llegó a la capital de México por primera vez en abril de 1819 y volvió a su país en 1821 . En ese año obtuvo el grado de bachiller en Leyes. Participó en movimientos en pro de la independencia de la isla y, ante el fracaso de los mismos, se vio obligado a huir a Estados Unidos. En 1825, invitado por Guadalupe Victoria, arribó por segunda vez a México; fue amigo y secretario de Santa Anna, llegó a ser diputado, ministro de Audiencia y director del Instituto Literario del Estado de México. En 1834 se opuso a las reformas liberales y en 1836 decidió volver a su patria, sin embargo retornó prontamente a México donde murió. Dirigió, junto con Claudio Linati y Florencio Galli el periódico El Irts y, en 1829, intervino en la publicación de La Miscelánea. Diccionarto, 1986.

65 Nació en la ciudad de México en 1800; ocupó diversos puestos públicos entre ellos el de fiscal del Supremo Tribunal de Justicia del Estado de México en 1828.

66 Participó en el Supremo Poder Ejecutivo del 1 de abril al 1 de mayo de 1823; de esta segunda fecha, al 1 de febrero de 1824. Por cierto, la notificación de su nombramiento como socio honorario del Instituto, fechada el 25 de marzo de 1826, es una de las dos que hasta el momento he bocalizado. Véase $\mathrm{NGN}$, Fondo Juan Hernández y Dávalos, 19-1.4503 [rollo 74]. Genaro García, Latin A merican Collection. 
En el acto que venimos describiendo, Andrés Quintana Roo, en su calidad de vicepresidente del Instituto, intervino con un discurso inaugural. También los señores Barquera, Sánchez de Tagle y Heredia leyeron com. posiciones poéticas. ${ }^{67}$ Conviene detenerse en las ideas expresadas por Quintana Roo, pues sus conceptos acerca de los propósitos de la institución confirman el carácter particular de la misma: el instituto, lo reitera, no estaría encargado de "enseñar o profesar una ciencia o arte particular, sino a cuidar del adelantamiento y perfección de todas". Objetivos que ya habían sido señalados en el proyecto presentado ante la Primera Secretaría de Estado: "promover y perfeccionar las ciencias, literatura y artes", ${ }^{68}$ no lejanos de aquellos invocados para el Instituto Nacional ideado en el Plan de la constttución visto líneas arriba, y tampoco de los asignados a una Academia Nacional en el Reglamento de Cádiz: "conservar, perfeccionar y propagar los conocimientos humanos". ${ }^{69}$

Para cumplir con sus fines, necesitaba formar, "un cuerpo compuesto de personas de una capacidad distinguida que, comunicándose sus luces y descubrimientos de todo género, puedan ponerse en estado de generalizar en el pueblo el gusto por la instrucciónn.$^{70}$ Es decir, se trataba de llegar a consolidar un órgano que condujera el desarrollo y las directrices del saber.

67 Memorias, 1826.

68 "Reglamento del Instituto de Ciencias, Literatura y Artes" , AGN, Ramo Justicia e Instrucción Pública, vol. $x$, ff. 15-27, cap. $1^{\circ}$, art. $1^{\circ}$, p. 1.

69 Historia, 1979, pp. $63-65$.

70 Memorias, 1826, p. 13.
Quintana Roo aludía también a las condiciones que hacían posible la existencia de instituciones como la puesta en pie: por una parte, la libertad obtenida con la independencia; $y$, por otra, el régimen de gobierno republicano, que está obligado, por su naturaleza, a tener "una conducta ilustrada" de protección y fomento de las luces pues, "la autoridad nunca está más sólidamente establecida que cuando se funda en la autoridad y moralidad del pueblo" ${ }^{71}$

Además, esas condiciones, como manifestó Quintana Roo en su discurso, permitían no solamente mantener la confianza de los hombres en los valores de la ciencia nueva sino que, en alusión nacionalista y de legitimación de la independencia de América, permitían el rápido desarrollo de la misma, pues si bien nacida en Europa, la ciencia, debido al régimen despótico que vivieron durante largos siglos los pueblos europeos, adelantó con lentitud. En cambio, en América "... [don. de] este mundo tiene todo nuevo, donde la naturaleza y las leyes concurren de consuno a levantar en ella a las ciencias, el templo más augusto que jamás haya tenido en la tierra". ${ }^{72}$

Entonces bien, las bases de libertad y democracia asentadas en "las repúblicas donde cada ciudadano forma una parte real $e$ indispensable del estado", no permitían la existencia de estudios despreciables en sus instituciones. ${ }^{73}$ Porque esos gobiernos debían

71 lbitd.

72 "Discurso inaugural" en Memortas, 1826, p. 22.

73 lbid., p. 21. 
su existencia "al voto libre de los ciudadanos que tienen los mismos intereses que el estado en el cultivo del espíritu y progresos que exigen la utilidad y ventajas de éste".

Finalmente, la misión de desarrollo de la ciencia y las artes, permitida por las instituciones republicanas, de acuerdo con los republicanos participantes en el Instituto y hecha suya, no quedaría completa si no era difundida, por lo que, expresó Quintana Roo, era preciso extender el conocimiento, la instrucción, a todos los ciudadanos. Pues sólo de esa manera era posible lograr adelantos para el Estado y dar una base democrática al nuevo régimen de gobierno. ${ }^{74}$

Así pues, las palabras del orador, revelan la enorme importancia y misión proyectada para este Instituto Nacional, como órgano director y difusor de las ciencias, dentro del nuevo Estado y régimen de gobierno que precisamente, hacía posible su funcionamiento. Bajo esas expectativas pues, quedó formalizada la existencia institucional de un cuerpo que se pretendía fuera rector del saber en el México independiente. ¿Cómo funcionaría semejante institución?

\section{ESTRUCTURA Y FUNCIONAMIENTO DEL. INSTTTUTO NACIONAL ${ }^{75}$}

El Reglamento del Instituto Nacional, formado en 1825, refleja una compleja

74 Ibid., p. 20.

75 Para comparar la estructura y el funcionamiento del Instituto Nacional de México, la Sociedad Nacional de las Ciencias y las Artes, propuesta por Condorcet para Francia, y la Academia Nacional española de Manuel José estructura. El funcionamiento general, puede resumirse, sería a la manera de las academias, ${ }^{76}$ pues se proponía la reunión de "los sabios" en las diferentes ciencias, además de los interesados en las mismas. La corporación tendría dos cabezas, dos mandos: una compuesta por un presidente, un secretario, un tesorero, un prosecretario; la otra por una junta directiva. ${ }^{77}$ Esta junta se integraría por nueve socios elegidos de entre aquellos que quedaran como integrantes de los grupos de las diferentes clases de ciencias, además del presidente y el secretario. Es decir, se entremezclaban funciones. Las atribuciones de esa junta estarían en examinar y vigilar los experimentos, observaciones, memorias y discursos que le fueran entregados para darlos a conocer ante el Instituto y resolver sobre lo que habría de leerse en las sesiones, además de otras actividades. ${ }^{78}$

El presidente, función desempeñada en 1826 por Lucas Alamán, se encargaría la primera vez, de elegir a los miembros de la junta. Los cargos de vicepresidente y de secretario, que recayeron en Andrés Quintana Roo y Ma-

Quintana, ffr. Condorcet, Informe, 1992, pp. 170-17, e Historia, 1979, pp. 63-65.

76 Las academias eran congregaciones de gente interesada en la discusión y conocimiento de temas científicos, artísticos y literarios. Las personas interesadas en promoverlos se agrupaban en torno a algún personaje o familia; llegaron a tener gran importancia en el desarrollo de las ciencias y las artes, por lo cual el Estado también consideró bajo su protección a algunas de ellas. En Francia, cada uno de las clases del Instituto de Francia recibía ese nombre. Enciclopedia, 1976, pp. 843-844, 855-856.

77 "Reglamento del...", AGN, Ramo Justicia e Instrucción Pública, vol. x, ff. 15-27.

${ }^{78} \mathrm{Ibid}$., cap. $7^{\circ}$, art. 23-25. 


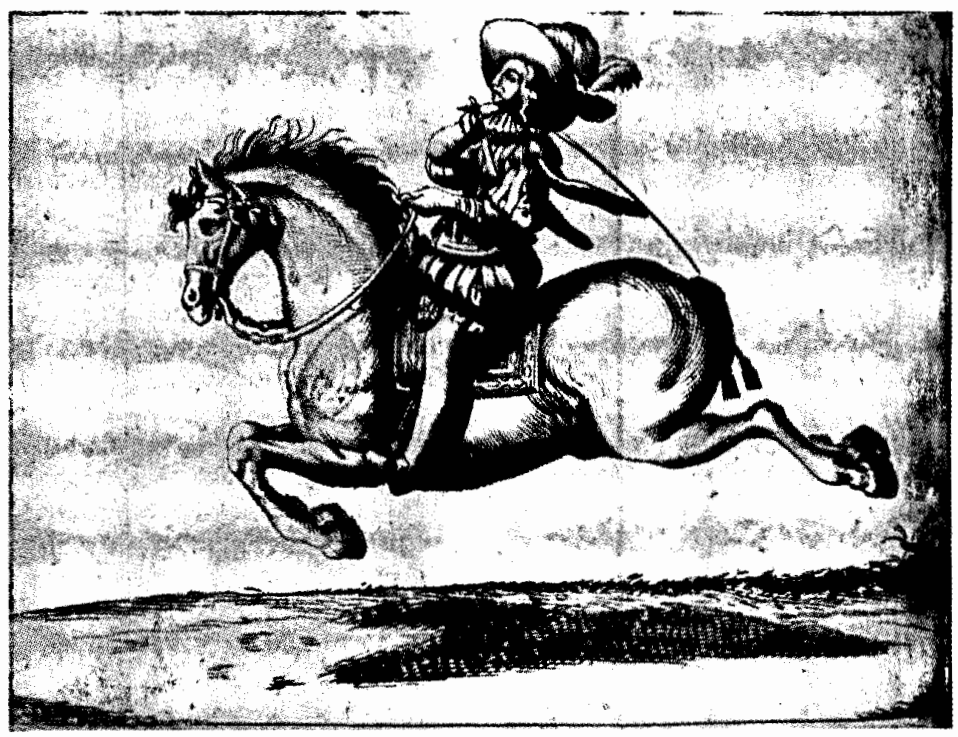

nuel Díez de Bonilla, respectivamente, ${ }^{79}$ tendrian el papel de auxiliares $y$ sustitutos del primero.

El funcionamiento práctico de la junta, con base en sesiones, se haría semanalmente y con un número mínimo de cuatro individuos; ${ }^{80}$ además de sesiones extraordinarias del instituto, que se realizarían solamente en caso de presentarse un asunto urgente $e^{81}$ y.con la presencia del presidente y los otros directivos. Esto es, en las manos de cuatro gentes podría quedar la decisión de las directrices de las ciencias y las artes.

Las sesiones tendrían también diverso carácter: generales del instituto p. 3 .

79 Águila Mexicana, 18 de abril de 1826 ,

80 "Reglamento...", cap. 13.

81 Ibid, cap. 12. y particulares de la junta: ordinarias o extraordinarias, públicas o privadas. ${ }^{82}$ En ellas se daría lectura a las memorias, documentos, cartas y otros papeles recibidos, se designarían las cuestioneso problemas a publicar para el conocimiento y participación de "los escritores", se calificaría la utilidad o mérito de los inventos o discursos remitidos y se votaría su premiación, así como también se discutiría la admisión de posibles socios. Además, como solía hacerse en ese tipo de instituciones, habría dos sesiones públicas solemnes para otorgar los premios y observar los progresos del Instituto. 83

82 Las primeras ordinarias, desarrollarían sus trabajos el día primero de cada mes, con la asistencia de 13 individuos al menos, $\boldsymbol{i b i d}$.

${ }^{83}$ Ibid., cap. 11. 
La participación de los socios, en sus diferentes modalidades - de número, corresponsales en los estados o en el extranjero, y honorarios-quedaba restringida a su lugar de residencia, $y$, todavía más, comprometido su voto. Pues solamente aquéllos con residencia fija en la capital tendrían derecho a ejercerlo; los segundos "los que estando en la capital o fuera de ella se admitieran en el instituto en razón de su celo y de sus facultades para su fomento", 84 contarian con voto consultivo; los terceros, los que el mismo instituto solicitase como socios, estarían en igualdad de voto que los anteriores; $y$, los últimos, los que pudieran prestar su ayuda en caso necesario, sólo tendrían voto consultivo cuando estuvieran en el lugar de residencia de la institución. Además, se distinguía a los socios honorarios pues se les invitaba "[con] su generosidad y patriotismo [a] contribuir con lo que gusten para los gastos".85

Por otra parte, para valorar el tipo de institución que se trataba de crear, resulta importante observar los requisitos exigidos para ser socio pues se pedía tener probidad, buen nombre, ser celoso del bienestar de la patria; los de número debían gozar de reconocimiento científico, literario $o$ artístico. ${ }^{86}$ En suma, se trataba de una selección de acuerdo a una posición social o de relaciones políticas. ${ }^{87} \mathrm{La}$

84 Ibid. cap. $3^{\circ}$, art. $6^{\circ}$.

$85 \mathrm{lbid}$.,

86 Ibid., cap. $3^{\circ}$, art. $8^{\circ}$

87 El secretario relata la forma como Lucas Alamán eligió a los miembros de la junta directiva, tomando la lista de socios y "a los que le parecieron los fue marcando con una señalita, democracia se ponía en práctica. ${ }^{88}$

En cuanto al objeto trascendental del Instituto, que eran las ciencias y las artes, se especificaban tres clases, ${ }^{89}$ cada una con sus respectivas secciones, a saber: " ${ }^{2}$ clase, de ciencias matemáticas, con secciones de geometría mecánica, astronomía, geografia, navegación y física general; $2^{a}$ clase, de ciencias naturales con secciones de química, mineralogía, botánica, economía rural, zoología y anatomía comparada; y $3^{a}$ clase, de literatura con secciones de gramática, poesía, elocuencia, historia y antigiiedades especialmente mexicanas". Por último, la adscripción de los socios a una de las clases y secciones se basaría en los conocimientos y distinción que se les reconociere.

Como puede verse, había la intención, sobre todo, de privilegiar el adelanto en aquellas ciencias consideradas prácticas, pues como también lo anotó Quintana Roo, mostraba cuánto predominaban aún las ideas ilustradas en México; los estudios especulativos se consideraban propios de las monarquías. ${ }^{90}$ Además, se incorporaba la historia de México ¿Era posible que tuviera éxito una institución de tal naturaleza en aquellos momentos?

sin haber hecho una gradación aparte de la que se determina en la lista general". Aguila Mexicana, 18 de abril de 1826 .

88 José Manuel Quintana lo había expresado en el Informe de 1814, la instrucción pública, en la primera enseñanza es universal, en la segunda, general y, en la tercera, particular. Esto quería decir que a los grados más altos llegaban algunos pocos.

89 "Reglamento...", f. 15, pp. 1-2.

90 "Discurso inaugural", en Memortas, 1826, p. 22. 
EI. FIN DEL INSTTTUTO Y EL SURGIMIENTO DE UNA DIRECCIÓN GENERAL DE ESTUDIOS (1826-1833)

El entusiasmo suscitado por la instalación oficial del Instituto Nacional, bajo el apoyo del gobierno, con una compleja organización y objetivos claros y definidos, no parece haber sido suficiente para sostenerlo después de 1826. Inclusive, apenas realizada la sesión extraordinaria para su instàlación formal, apareció en el Águila Mexicana una carta firmada bajo las siglas $S$. E. Y.A., que reclamaba la forma en que se había organizado el acto. En particu. lar, porque no se había hecho mención del "principal promotor" de su creación: José Ma. Tornel. Y se culpaba al secretario, Diez de Bonilla, porque "lo dejó de señalar sin dar cuenta al instituto de este parecer, y obrando con una autoridad que sus consocios no le han confiado...".91 Diez de Bonilla contestó argumentando que la elección la había hecho Alamán, en su calidad de presidente y en vista de no poder asistir a la inauguración; además, esta designación recayó en Quintana Roo por constar su asistencia asidua a las sesiones de la Junta. La contestación finalizaba diciendo que "Seguramente [el anónimo personaje] no se ha impuesto del reglamento ni de lo ocurrido en varias sesiones. ${ }^{n 92}$

Atrás de estos reclamos hechos en el medio portavoz de los yorkinos, el Águila Mexicana-y Tornel era uno de ellos-, se mostraban las fuertes desavenencias políticas que existian entre

91 Agutla Mexicana, 13 de abril de 1826, p. 3. 92 Aguila Mextcana, 18 de abril de 1826, p. 3. los organizadores y participantes del Instituto que, por otra parte, dejaban prever un pronto fin para el proyecto.

Después de estos momentos, las escasas y aisladas referencias sobre la institución empiezan a definir dos posturas sobre el financiamiento asignado: por una parte, salvarlo para conservar y consolidar la institución; por la otra, se intenta su transferencia y el paso de algunas de las funciones del Instituto a otro de los órganos administrativos con importante papel dentro del proyectado sistema educativo: la dirección general de éstudios.

Así, la partida presupuestaria de 1828 , incluyó la asignación de 6000 pesos para su subsistencia. ${ }^{93}$ Para fines del mismo, la crisis económica de México alcanzó un punto más severo, mientras que la discordia política a causa de las elecciones presidenciales y el asunto de la expulsión de los españoles agravaron más las dificiles condiciones que se vivían. ${ }^{94}$ A pesar de lo cual, en las primeras sesiones del Congreso de 1829, al ser leídos los informes de los ministerios y entre los asuntos más urgentes que, como es de suponerse, eran los relativos a los problemas políticos vigentes, Juan de Dios Cañedo, ministro de Relaciones, dio a conocer en su Memoria la paralización de las actividades del Instituto "por falta de fondos propios" pues de los 600 pesos asignados, hasta octubre de 1828 sólo se le habían dado 300.95

93 Dublán y Lozano, Legislación, 1877, vol. 2, p. 54 .

94 Sims, Descolonizact6n, 1982 , p. 64.

95 Memoria, 1829; como fue visto arriba, se le habian asignado 6000 , sin embargo, en la memoria de 1829 se indican 600 . 
Un año más tarde, Lucas Alamán indicó en su Memoria que el Instituto Na. cional no había continuado sus sesiones, tal vez por "falta de auxilio o lo inadecuado de su reglamento".96 En. tonces propuso su refundición con una Dirección de Instrucción Pública proyectada por él y que tendría la fun. ción de administrar "los fondos de los Colegios mayores y de la Universidad, supervisar su reorganización para evitar la duplicación de cursos en los distintos colegios; nombrar a los profesores y uniformar la educación en los tres niveles" ${ }^{97}$ Este órgano administrativo, al que dedicó nuevamente aten. ción en 1831 porque, de acuerdo con él, no habría [adelanto] mientras no se organice la dirección de estudios que deberá tener entre sus atribuciones la de atender a este ramo esencialísi. mon, 98 terminaría por imponerse en los años subsecuentes.

En efecto, dos años después, dentro de las reformas educativas liberales encabezadas por Valentín Gómez Farías, se establecía la creación de una Dirección General de Instrucción Pública y, además, el decreto de 26 de octubre de 1833 consignó y puso a cargo de la misma, entre otros, los fondos asignados al instituto en $1828 .{ }^{99}$ Seguramen.

96 Alamán, Memorta, 1830, p. 225.

$97 \mathrm{fbid}$.

9 A lamán, Memoria, 1831.

99 El decreto señalaba "se consignan y ponen a cargo de la dirección de instrucción pública, con los gravámenes que actualmente reportan, los fondos y fincas siguientes: $1^{\circ}$ el convento y templo de San Camilo, con sus fincas urbanas; $2^{\circ}$ el hospital y templo de Jesús, con las fincas urbanas que pertenecían al duque de Monteleone, aplicados a la instrucción primaria por ley de 22 de mayo de $1833 ; 3^{\circ}$ el antiguo y nuevo hos. te esta medida le dio fin, pues después ya no hay referencias sobre el mismo.

La confirmación de su desaparición, sin ser detallada, la hace Juan de Dios Arias, autor en el México a través de los siglos de la parte referida al mo. mento que estamos tratando; la causa la atribuye a los cambios políticos que impidieron fructificara un proyecto como éste, quedando sólo "de recuerdo y de modelo" para nuevas instituciones de su tipo. ${ }^{100}$

PosData. El PROBlema

DE LOS INSTTTUTOOS LITERARIOS

Y DE LA INSTRUCCIÓN PUBLICA

El Instituto Nacional de Ciencias y Artes, eje del sistema educativo centralizado que se intentó formar en México en 1823, tenía su complemento en los institutos que iban a ser creados en las provincias. En éstas, después de 1824, también tomó fuerte impulso la idea de formar un sistema de instrucción pública "centralizado", como base para

pital de Belén; $4^{\circ}$ el hospicio de Santo Tomás con su huerta; $5^{\circ}$ El edificio de la A ntigua Inquisición aplicado a la Academia de San Carlos por la ley de 20 de mayo de $1831 ; 6^{\circ}$ el templo del Espíritu Santo con su convento; $7^{\circ}$ los ocho mil pesos que por el art. 5 de la ley de 1 de mayo de 1831, se aplicaron al Ayuntamiento para establecimiento de escuelas; $8^{\circ}$ los sets mil pesos que asigna la ley de 28 de enero de 1828, para gastos del Instituto de Ciencias, Literatura y Artes; $9^{\circ}$ los 3000 pesos que la misma ley concede para fomento de escuelas lancasterianas de primeras letras en el Distrito; $10^{\circ}$ la imprenta establecida en el hospital de pobres, que deberá precisamente mantenerse en este establecimiento. Dublán y Lozano, Legislación, 1887, vol. n, p. 574.

100 Riva Palacio, Méxtco, 1984, p. 139. 
la secularización de la enseñanza. Las acciones de los congresos estatales estuvieron encaminados a conseguirlo.

Entre las propuestas conocidas, destaca la que expresó José María Luis Mora, diputado al Congreso Constituyente del estado de México, pues manifestó su preocupación por crear un establecimiento de educación religiosa y literaria, sostenido con las contribuciones de los partidos del estado y en el que habría cátedras innovadoras: de gramática latina y castellana; francés e inglés; lógica y filosofía general; 101 economía política; derecho público, constitucional y principios de legislación; derecho romano, canónico y patrio; dogma y moral religiosa y, por último, dibujo. ${ }^{102}$ Era, en todos sentidos, un instituto provincial, para la instrucción pública de segunda enseñanza.

Los debates desarrollados en el Congreso del Estado de México, para la instalación del que se llamó Instituto Literario, continuaron con mayor intensidad entre 1827 y 1828 . Finalmente, aún sin ser definitivo, un establecimiento de esa clase fue inaugurado en Tlalpan en 1828. ${ }^{103}$

La fundación de establecimientos semejantes ocurrió también en los estados de Jalisco (1826), Oaxaca (1827), Chihuahua (1826) y Zacatecas (1831). ${ }^{104}$ Estos fueron los primeros

101 La única versión accesible del discurso omite los artículos $4^{\circ}$ y $5^{\circ}$. Hasta el momento no hemos localizado el original que permita conocerlo integro.

102 Mora, "Proposición", 1967, pp. 63-67. Sesión de 17 de noviembre de 1824 .

${ }^{103}$ Herrejón, Fundactón, 1978.

104 En otro lugar he hecho el estudio de las institutos literarios, creados en los estados para ofrecer a los jóvenes los estudios de segunda y tercera enseñan. za. Los primeros lugares que contaron con una institución bajo ese nombre, debe reconocerse, fueron de fuerte orientación federalista ${ }^{105}$ y también, debe tenerse presente, formaron parte de los esfuerzos tendientes a estruc. turar un sistema de instrucción pública en los estados.

En cada uno de los lugares donde hubo un instituto, éste no quedaba como una entidad aislada sino dentro de un sistema, de una estructura. Pues los planes educativos generalmente examinaron todos los aspectos que convenían a la mejor atención de la educación. Así, se hablaba de la gratuidad y la uniformidad de la instrucción pública; de la primera, segunda, tercera y hasta, en el caso de Jalisco, cuarta enseñanza; se definían los establecimientos para cada uno de esos niveles y, además, se ordenaba, invariablemente, la creación de una Dirección General de estudios o Junta Directiva. ${ }^{106}$

características de los Institutos Literarios de Ja. lisco, Oaxaca, Chihuahua, Estado de México y Zacatecas. Véase Ríos, "Educación", 1992.

105 Sin duda, la problemática en torno a los institutos literarios, ofrece innumerables interrogantes, una de ellas es su vinculación con el liberalismo, considerada de facto por la historiografía. Sin embargo, por el momento, la única afirmación que nos permite hacer el estado de la investigación acerca de esas instituciones, es la que se sigue en este trabajo.

106 Los planes a que me refiero en concreto son los decretados por las legislaturas de Jalisco (1826) y Zacatecas (1831), en los que existe para entonces esta división. Véase Plan, 1826, Plan, 1831, también Ley, 1826, pp. 1-4; Decreto núm. 12 del estado de Chihuahua, firmado por el go bernador José Antonio Ruiz de Bustamante en 
Es indudable, por lo expuesto hasta aquí, que en los primeros proyectos educativos, bien de carácter nacional o estatal, existió la idea de que hubiera un sistema de educación pública centralizado. Y, al menos en lo que se refiere a la propuesta del Plan de 1823, que existiera relación entre los institutos provinciales y un Instituto Nacional. La relación formal, por lo que se conoce hasta el momento, no existió, salvo comunicaciones a título personal entre quienes participaron como profesores o como autoridades en los institutos. ${ }^{107}$ Sin embargo, parece que, a fin de cuentas, la creación de una y otras instituciones, la reforma de las existentes hacia los mismos moldes de las nuevas, la formación gradual de fondos para la instrucción pública, la paulatina jerarquización de los estudios así como los cambios en los contenidos de los saberes, revelan la importante transición que se venía gestando, de una antigua forma de enseñanza a otra nueva, es decir, hacia su secularización.

El nuevo régimen, como lo señaló Quintana Roo, permitió acelerar el proceso, iniciado, no hay que soslayarlo, bajo la influencia de Cádiz, por tanto, de Francia. Además de esto, las modalidades adoptadas para el régimen de gobierno republicano, las divergencias políticas e ideológicas por impo-

septiembre 3 de 1827 . AGN, Ramo Justicia e Instrucción Pública, vol. 92, ff. 150.

107 Por ejemplo, cuando se planteó en Zacatecas la fundación de una Casa de Estudios en la ciudad de Jerez, cercana a aquella capital, se pidió consejo a quienes dirigían el Instituto de Ciencias de Jal isco. Archivo Histórico de Zacatecas, Ramo Jefatura Política, serie Instrucción Pública, subserie generalidades, caja 3 . ner determinado proyecto de nación, así como las reales dificultades económicas y las particularidades regiona. les, confluyeron todas en conformar la características del incipiente sistema educativo nacional.

Si en la historia que he querido recuperar, no tuvo éxito -tanto que su historia se perdió- la institución central que tendría el papel fundamental de promover, conservar y difundir las ciencias y las artes, en cambio, en los estados, los institutos literarios dedicados a impartir la segunda y tercera enseñanza, comenzaron su historia. Queda pues, para avanzar en la comprensión y explicación de la secularización de la enseñanza y del papel de los institutos literarios en ella, emprender, en el futuro, el estudio regional de éstos.

\section{ANEXO \\ MIEMBROS DEL INSTTTUTO DE CIENCIAS, LITERATURA Y ARTES (1826) ${ }^{108}$}

\section{Socios de numero}

1. Alamán, Lucas

2. Quintana Roo, Andrés

3. Villaurrutia, Jacobo

4. Espinosa de los Monteros, José

5. Río, Andrés del

6. Cotero, José Manuel

7. Castro, Manuel

8. Tornel, José María

9. Sánchez de Tagle, Francisco

10. Carpio, Manuel

108 "Listas de socios del Instituto de Ciencias, Literatura y Artes. Instalación solemne verificada el día 2 de abril de 1826", en Memorias, 1826, Biblioteca Nacional de México, Fondo Lafragua (708). 
11. Argüelles, Manuel

12. Gordoa, Luis

13. Jáuregui, José María

14. Piña, Joaquín

15. Jiral, Mariano José

16. Barquera, Juan Wenceslao de la

17. Guerra, Benito José

18. Mier y Terán, Manuel

19. Yãñez, José Isidro

20. Mora, José María

21. Valentín, Miguel

22. Llave, Pablo de la

23. Tejada, Manuel

24. Cervantes, Vicente

25. Bustamante, José María

26. Orbegoso, Juan

27. Fagoaga, José María

28. Alamán, Tomás

29. Moral, Tomás Ramón del

30. Rincón, Manuel

31. Rojas, Joaquín

32. Balenchana, Juan

33. Vázquez, José María

34. Alegre, José María

35. Mora, Ignacio

36. Paz, José Agustín

37. Patiño, Pedro Ixtolinque

38. Ceballos, Juan

39. Arellano, Ignacio

40. Rodríguez, Francisco María

41. Rodríguez, Juan

42. Navarro, Fernando

43. Guerrero, José María

44. Torre Blanca, José Mariano

45. Navarto, Cástulo

46. Álvarez, Ignacio

47. Cocho, José

48. Ortega, Francisco

49. Medina, Antonio

50. Diez de Bonilla, Manuel

Socios corresponsales en los estados

1. Arroyo, N., canónigo (N. L.)

2. Baca Ortiz, Santiago (Dgo.)

3. Becerra, Luciano (Pue.)

4. Bustamante, Benigno (Gto.)
5. Cal, Antonio (Pue.)

6. Camacho, Ignacio (Qro.)

7. Camacho, Sebastián (Ver.)

8. Cañedo, Juan de Dios (Jal.)

9. Castillo, Florentino (Oax.)

10. Couto, José María (Valladolid)

11. Díaz León, Ildefonso (SLP)

12. Echandía, José María (Californias)

13. Esteves, Pedro Agustín, Ilmo. Sr. (Yuc.)

14. Fajardo, Domingo (Yuc.)

15. García, Francisco (Zac.)

16. Gastañeta, Vicente (Zac.)

17. Gavilán, Miguel (Dgo.)

18. Garcés, D. N., coronel (SLP)

19. Guzmán, José María (Dgo.)

20. Lazo de la Vega, Domingo (Gto.)

21. López Bueno, Manuel (Ver.)

22. Martínez, Florentino (Chih.)

23. Méndez, Juan (Gto.)

24. Murguia, José Maria (Oax.)

25. Múzquiz, Rafael (Coah.)

26. Narváez, José

27. Ozores, Félix (Qro.)

28. Oteiza, Joaquín (Qro.)

29. Pastor Morales, Juan José (Valladolid) (Pue.)

30. Pérez, Antonio, llmo. Sr. obispo de

31. Pérez, José María (Ver.)

32. Portugal, Cayetano (Jal.)

33. Quintana, José Matías (Yuc.)

34. Rodríguez Castelazu, José Joaquín (N. Mex.)

35. Sanabria, Juan Nepomuceno (Zac.)

36. Sancho, Dionisio (Zac.)

37. Tresguerras, Francisco (Gto.)

38. Treviño, Alejandro (N. L.)

39. Urquida, José (Chih.)

\section{Socios corresponsales extranjeros}

1. Ackerman, Ricardo (Londres)

2. Blanco White, José (Londres)

3. Bolívar (Colombia)

4. Campbell, Pedro (Londres)

5. Canga Argüelles, Josê (Londres)

6. Caning, Jorge (Londres)

7. Clay, Enrique (Filadelfia) 
8. Gual, Pedro (Colombia)

9. Humboldt, barón de (París)

10. Lafayette, general (París)

11. Makinstons, Santiago (Londres)

12. Malinas, Sr. arzobispo de (París)

13. Mayorga, Juan de Dios (Guatemala)

14. O'Farril, Sr. general D. Gonzalo (París)

15. Paula, Francisco de Santander (COlombia)

16. Poinset, Joel R. (Filadelfia)

17. Pradt, Gregoire, Mr. (París)

18. Pradt, Mr. (París)

19. Rivadavia, Bernardino(Buenos Aires)

20. Santa María, Miguel (Colombia)

21. Varela, Félix (Filadelfia)

22. Ward, Enrique (Londres)

23. Zulzer, Luis (Países Bajos)

\section{Socios Honorarios}

1. Acevedo, Pedro

2. Aldec, Gerónimo

3. Alva, Ignacio

4. Anaya, Pablo

5. Arce, Juan Antonio

6. Azorrey, José María

7. Bárcena, Manuel

8. Barragán, Miguel

9. Berazueta, J. Ignacio

10. Bocanegra, José María

11. Bravo, Nicolás

12. Bustamante, Ignacio

13. Cabrera, José María

14. Calvo, Rafael

15. Castillo y Quintero, Juan N. del

16. Cervantes, Miguel

17. Couto, José Manuel

18. Covartubias, José María

19. Diez de Bonilla, Mariano

20. Domínguez, Miguel

21. Echávarri, José Antonio

22. Elizalde, Juan Manuel

23. Espinosa, José María

24. Esteva, José Ignacio

25. Fagoaga, Francisco

26. Fagoaga, José Francisco

27. Fuente, José
28. Garayalde, José María

29. García, Carlos

30. García, Eusebio

31. Godoy, Ignacio

32. Gómez Anaya, Cirilo

33. Gómez Pedraza, Manuel

34. González Angulo, Bernardo

35. Guerrero, Vicente

36. Guridi Alcocer, Miguel

37. Guzmán, Juan

38. Heras, Manuel

39. Heredia, José María

40. Herrera, José Joaquín de

41. Herrera, José Manuel de

42. Herrera, Mariano

43. Ibarra, Cayetano

44. Inclán, Ignacio

45. Iturralde, José María

46. Izita, José Bernardo

47. Larrainaga, José Antonio

48. Lombardo, Francisco

49. Maldonado, Dimas

50. Mangino, Rafael

51. Maniau, José Nicolás

52. Mestre, José María

53. Michaus, Ángel

54. Michelena, Mariano

55. Molinos del Campo, Francisco

56. Morales, Juan

57. Morán, José

58. Murfi, Tomás

59. Múzquiz, Melchor

60. Nájera, Ignacio

61. Navarrete, J. N.

62. Negrete, Pedro Celestino

62. Obregón, Pablo

63. Oláez, Nicolás

64. Oller, José María

65. Paso y Troncoso, Pedro del

66. Paula Villegas, Francisco de

67. Peña y Peña, Manuel

68. Pérez Gálvez, Juan

69. Posadas, Manuel

70. Ramos Arizpe, Miguel

71. Rincón, José

72. Rocafuerte, Vicente

73. Rojas, José

74. Ruz, José Domingo 
75. Salazar, José A ntonio

76. Sánchez, José Vicente

77. Sendoya, Francisco

78. Velasco, Antonio

79. Victoria, Guadalupe

80. Villaurrutia, Ciro

81. Zavala, Lorenzo

\section{BIBLIOGRAFIA}

-Alamán, Lucas, Documentos diversos (inéditoso muy raros), vol. I, compilación de Rafael Aguayo Spencer, Editorial Jus, México, 1945.

- Memoria que el secretario de Estado y del Despacho de Relaciones Interiores y Exteriores presenta al Soberano Congreso Constituyente sobre los negocios de su cargo, leida en la Sesión de 8 de noviembre de 1823, Impresa de Orden del Soberano Congreso. Imprenta del Supremo Gobierno en Palacio, México, 1823.

__, Memoria de la Secretaría de Estado y del Despacho de Relaciones Interiores y Exteriores, leida por el secretario del Ramo en la Cámara de Diputados el día 12 de febrero de 1830 , y en la de senadores el día 13 del mismo, Imprenta del Águila dirigida por José Ximeno, calle de Medinas, núm. 6, México, 1830.

, Memoria de la Secretaría de Estado y del Despacho de Relaciones Interiores y Exteriores presentada por el secretario del Ramo a las Cámaras del Congreso General en cumplimiento del artículo 120 de la Constitución y leída en la de Diputados el día 7; y en la de Senado. resel 8 de Enero de 1831, Imprenta del Águila dirigida por José Ximeno, México, 1831; en Alamán, Documentos, pp. 243-338.

-Almada, Francisco, "La reforma Educativa desde 1812" en Historla Mexicana, vol. vi(1), núm. 65, jul-sept. 1967, pp.102-125.

-Anna, Timothy E., El imperio de Itur. bide, Editorial Patria, México, 1991 (Colección Los noventa, 70).
-Bravo Ugarte, José, La educación en México (...1965) con una introducctón sobre la educacton en el mundo, Editorial Jus, México, 1966 (Colección México Heroico).

- Condorcet, Informe sobre la organización general de la instrucción pública presentada a la Asamblea Nacional Legislativa, en nombre del Comité de Instruccion Pública, el 20 y 21 de Abril de 1792, en Escritos Pedag6gicos, Editorial Calpe, Madrid, 1992 (Colección Universal, núms. 554 y 555 ).

-Costeloe, Michael E., La primera republica federal de México (1824-1835). Un estudio de los partidos politicos en el México independiente. Fondo de Cultura Econômica, México, 1983.

-Diccionario de historia, biografía y geografia de México, $5^{a}$ ed., 3 vols., Porrúa, México, 1986.

-Dublán y Lozano, Legislactón mexica. na o colección completa de las disposiciones legislativas expedidas desde la independencia de la Repablica, edición oficial, Imprenta del Comercio de Dublán y Chávez a cargo de M. Lara (hijo), México, 1887.

-Enciclopedia Universal Ilustrada europeo americana, Espasa Calpe, MadridBarcelona, 1976.

-Green, Stanley C., The mexican repu. blic; the first decade 1823-1832, University of Pittsburgh, Pittsburgh, 1987, (Pitt, Latin American Series).

- Guedea, Virginia, En busca de un gobierno alterno: los guadalupes de México, UNAM-IH, México, 1992 (Serie Historia Novohispana, 46).

-Guerra, François-Xavier, México, del antiguo régimen a la revolución, 2 vols., Fondo de Cultura Económica, México, 1988 (Sección de obras de historia).

-Hale, Charles, A., El liberalismo mexicano en la época de Mora, 1821-1853, 6 ed., Siglo XXI Editores, México, 1985.

-Hamnett, Brian R., "Factores regionales en la desintegración del régimen colo- 
nial en la Nueva España: El federalismo de 1823-1824" en Inge Buisson (comp.), Problemas de la formación del Estado y la nactón en Hispanoamérica, Bohlau Verlag, Colonia, 1984.

-Herrejón Peredo, Carlos (estudio y selección), Fundactón del Instituto Literario del Estado de México, Universidad del Estado de México, México, 1978.

-Mialaret, Gaston, y Jean Vial (comps.) Histotre Mondiale de l'éducation, vol. 2, (1515 a 1815), Presses Universitaires de France, París, 1985.

-Historia de la educación en España. Textos y documentos, 2 vols., prólogo de Manuel Puelles de Benítez, Secretaría General Técnica del Ministerio de Educación, Madrid, 1979.

-Jovellanos, Gaspar Melchor de, "Bases para la formación de un plan general de instrucción pública" en Obras completas, vol. I, Ediciones Atlas, Madrid, 1951.

-Larroyo, Francisco, Historia comparada de la educación en México, $15^{\mathrm{a}} \mathrm{ed}$., Porrúa, 1981.

-Meneses Morales, Ernesto, Tendencias educativas oficiales en México. 1811 . 1911, Porrúa, México, 1983.

-Mora, José María Luis, "Proposición sobre instrucción pública hecha por el Dr. José María Luis Mora al Congreso del Estado de México, siendo diputado del mismo", en Escuelas laicas. Textos y documentos. Empresas Editoriales, México, 1986 (El Liberalismo mexicano en pensamiento y acción, 7 ). , Obras completas, investigación, recopilación, selección y notas de Lilian Briseño Senosian, Laura Solares Robles y Laura Suárez de la Torre, Prólogo de Eugenia Meyer, SEP-Instituto de Investigaciones Dr. José María Luis Mora, México, 1986.

-Ley de Instruccí́n Pública del Estado de Oaxaca, El Instituto de Ciencias y Artes del Estado. Los años de formación, (1826), Instituto de Investigaciones en $\mathrm{Hu}$ manidades-Universidad Autónoma Benito Juárez de Oaxaca, 1990.
-Mérida, Eloísa "El concepto de instrucción pública. Sus notas características en Campomanes, Jovellanos, Cabarrús y Quintana" en Ossenbach, y Puelles, Revolución, 1990, pp. 117-140.

-Memorias del Instituto de Ciencias, Literatura y Artes. Instalactón solemne verificada el día 2 de abril de 1826, vol. I, Imprenta del Supremo Gobierno en Palacio, México, 1826.

-Memorta de La Secretaria de Estado y del despacho de Relaciones interiores y exteriores de la Republica mexicana, leida en la Cámara de Diputados el 8 y en la de Senadores el 10 de enero de 1829. Imprenta del Águila dirigida por José Ximeno, México, 1829.

-Ossenbach Sauter, Gabriela, y Manuel Puelles de Benitez (comps.), La revolucion francesa y su influencia en la educación de España, Universidad Nacional de Educación a Distancia, Universidad Complutense de Madrid, Madrid, 1990.

- Plan de la Constitución Política de la Nactón (1823) en Tena Ramírez, Leyes, 1975.

-Plan Genenal de Instrucción Publica. para el estado de Jalisco, 26 de marzo de 1826.

-Plan general de Instrucción Páblica para el Estado de Zacatecas. Primera parte, Zacatecas, Secretaría de Educación, 1831

-Quintana, Manuel José, Obras. Con un estudio critico biografico por Ramón García, Librería Española de Garnier Hermanos, París, 1882.

-, "Informe de la junta creada por la regencia para proponer los medios de proceder al arreglo de los diversos ramos de instrucción pública", 9 de septiembre de 1813, en Obras Completas, Madrid, 1946 (Biblioteca de Autores Españoles, XIX).

-Ramos Escandón, Carmen, "Planes educativos en el México independiente", tesis de Maestría en Artes, Universidad de Austin, Texas, 1972.

-Ríos Zúñiga, Rosalina, "Educación y 
secularización. La problemática de los Institutos Literarios en el siglo Xxx (18241857)", tesis de licenciatura en historia, Facultad de Filosofia y Letras, UNAM, 1992.

-Riva Palacio, Vicente, México a través de los siglos, Editorial Cumbre, México, 1984.

-Rodríguez O., Jaime, "Intellectuals and the mexican constitution of $1824^{\prime \prime}$ en Roderic A. Camp, Charles A. Hale y Josefina Vázquez, (comps.), Los intelectuales y el poder en México, Memorias de la vi Conferencia de Historiadores Mexicanos y Estadunidenses, El Colegio de México-University of California, 1991.

_, "La independencia de la América española: una reinterpretación", Historia Mexicana, vol. XII (1), núm. 167, enero-marzo 1993, pp. 571-620.

-Sims, Hatold, Descolonizactón en Mé$x i c o$. El conflicto entre mexicanos y espafioles (1821-1831), Fondo de Cultura Económica, México, 1982 (Sección de obras de historia).

-Staples, Anne, "Alfabeto y catecismo, salvación del nuevo país" Historia Mexicana, vol. XXxx (1), núm. 113, julio-septiembre 1979, pp, 35.58.

, "Los Institutos científicos y literarios de México" en Memoria del primer encuentro de historia sobre la Universidad, UNAM/CESU, México, 1985, pp. 43-54.

"Panorama educativo al co-

mienzo de la vida independiente ${ }^{n}$ en Josefina Vázquez, Ensavos sobre historia de la
Educación en MExico, $2^{2}$ ed., El Colegio de México, México, 1985, pp. 117-170.

- Educar:panacea del México independiente (Antología de Documentos), SEP Cultura-Ediciones El Caballito, México, 1985 (Biblioteca Pedagógica).

-Tanck de Estrada, Dorothy, "Las Cortes de Cádiz y el desarrollo de la educación en México" en Historia Mexicana, vol. XXxx, núm. 1 (113), julio-septiembre 1979 , pp. 3-34.

- La educación ilustrada, 1786-1836. Educación primaria en la ciudad de México, $2^{2}$ ed., El Colegio de México, México, 1984 (Centro de Estudios Históricos).

-Tena Ramírez, Felipe, Leyes fundamentales de México, $6^{\mathrm{a}}$ ed., Porrúa, México, 1975.

-Vázquez, Josefina, Nacionalismo $y$ educación en México, El Colegio de México, México, 1970.

-Valle López, Ángela del, "La huella de dos pedagogos de la revolución francesa -Talleyrand-Perigord y Condorcet- en los proyectos educativos de Jovellanos y Quin. tana" en Ossenbach y Puelles, Revolución, 1990, pp. 141-172.

-Vidal, Salvador, "Señor Francisco Gar. cía Salinas. Tata Pachito (Estudio biográfico y político)" en Javier Enríquez y Jorge Denegre Vaught (comps.), Homenaje a Franctsco García Sallnas., Gobierno Constitucional de Zacatecas, Universidad Autónoma de Zacatecas, México, 1986. 


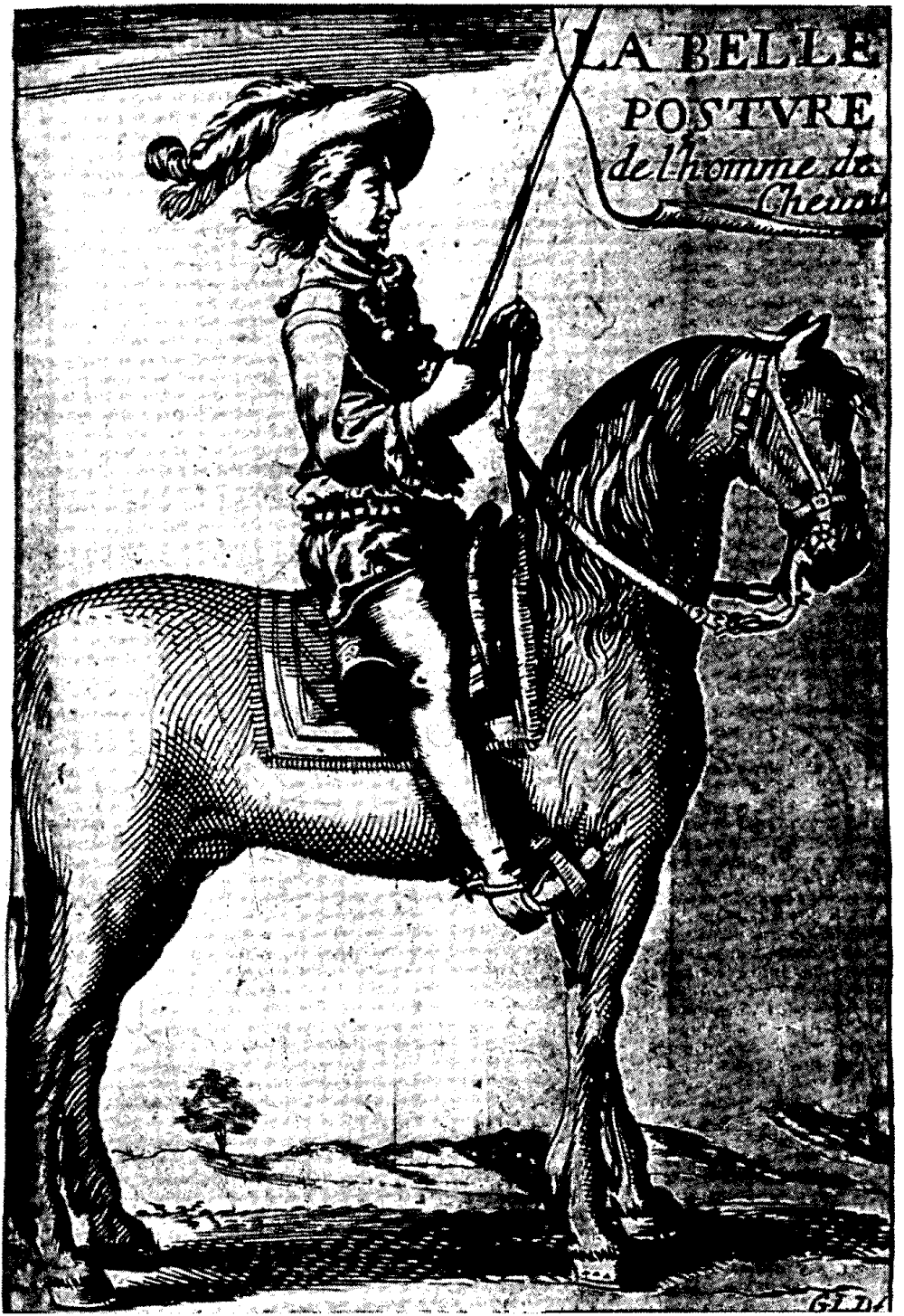

